\title{
Passive Robustness Computation Algorithm for Advance Time Disturbances in Manufacturing Job-shops
}

\author{
Nabil JERBI ${ }^{1 *}$, Simon COLLART-DUTILLEUL ${ }^{2}$ \\ ${ }^{1}$ University of Sousse, Ecole Supérieure des Sciences et de la Technologie de Hammam Sousse, \\ Rue Lamine Abassi, Hammam Sousse, 4011, Tunisia \\ nabil.jerbi@isetso.rnu.tn (*Corresponding author) \\ ${ }^{2}$ Université Lille/Nord de France, Institut Français des Sciences et Technologies des Transports Architectures \\ et Réseaux (IFSTTAR/COSYS/ESTAS), Rue Elisée reclus 59666 Villeneuve d'Ascq, France \\ simon.collart-dutilleul@ifsttar.fr
}

\begin{abstract}
In this paper the authors are interested in passive robustness of manufacturing job-shops with time constraints and particularly in the passive robustness facing advance time disturbances. The operation times are included between a minimum and a maximum value. P-time Petri nets are used for modeling. An algorithm allowing the computation of an advance passive robustness margin is elaborated relying on a study of the available local robustness at the synchronisation transition of a mono-synchronized subpath. Moreover, a lemma is stated regarding constraints violation where the margin is calculated. The occurrence of a time disturbance respecting both the lemma conditions and the algorithm margin does not involve any constraints violation. The established results are illustrated step by step on examples of a given workshop.
\end{abstract}

Keywords: P-time Petri net, Passive robustness, Time disturbance, Time constraints, Manufacturing.

\section{Introduction}

Time critical systems, including minimum and maximum constraints for operation duration, correspond to various industrial processes which may be found in pharmaceutical, chemical and food industries [14], in electronic components and processors, etc. $[2,16]$. The existence of a maximal bound for an operation execution gives a particular mathematical structure to the model to be studied, as described in $[4,11]$. Several works mainly focusing on robustness towards delay occurrences can be found in the state of the art concerning manufacturing [1, 10], or transport [17]. This robustness approach has been extended to processes including non-temporal parameter belonging to a validity interval [13]. In all these cases, bounds ensue from product specification. It means that an out of range operation provides a product which is not usable and potentially dangerous.

The proposed paper wants to focus on advance phenomenon, despite the fact that delay and advance are considered as dual symmetric phenomena. Common errors of understanding probably come from the fact that delay management is well known in the literature. In this case, an efficient policy is to perform "as fast as possible" in order to recover. Actually, from a general point of view, this particular functioning cannot be applied for a process with maximum time constraints.

\section{The example of the Canadian student}

In order to give a practical study case, let us consider the problem faced by a Canadian student.
He wants to catch the bus of 7 o'clock in order to attend a course at 8 in his university, but he does not want to wait more than 20 minutes because of the coldness of the weather. Clearly, if he is ready and goes to the bus-stop at 6 , he will wait one hour under the snow. Then, it is obvious that a good policy is to arrive between zero and twenty minutes before 7 o'clock. The main conclusion of this example is that the as soon as possible policy is not always possible.

As this counter-example is quite simple, nobody is allowed to claim on a complex system that the "as soon as possible functioning" is feasible without holding a dedicated proof.

Another way of standing the problem is to integrate the control problem formulation proposed by Declerck, knowing that the existence of a solution is not proven in the general case [5].

\section{Advance problems}

The previous example is provided as a simple illustration that arriving in advance may result a problem. Putting a product in an acid tank may degrade it, whereas the instant of going out of the tank is fixed by a predefined hoist movement.

From an industrial point of view, advance and delay are the two faces of the same synchronization problem. When an advance is put on a product, all the uses of resources and corresponding actions will be affected by this time shift: all the planned actions may be considered as late. In a modern 
manufacturing organization, the diversification of suppliers is a way of dividing the industrial risk. On the other hand, this diversity may produce diversity in the quality of wares as well. Cutting the product may be faster. More generally, some operations may not be needed when the core material has been already processed. Skipping the corresponding operation will produce an advance with regard to the reference scheduling.

After introducing maximum duration constraints in manufacturing area, the following section presents a dedicated tool named P-time Petri nets [11]. In the third section, they are used to formalize schedule design in manufacturing systems from a functional point of view. Then, the robustness towards time constraints is studied, focusing on the advance cases. A dedicated algorithm, built upon local passive robustness computation, and a specific lemma regarding constraints violation are provided. They are illustrated through various examples. In the conclusion of the paper some prospective works are proposed.

\section{P-time Petri net}

\subsection{Definition}

The formal definition of a P-time Petri net is given by a pair $<$ R; IS $>$, where [11]:

- $\quad \mathrm{R}$ is a marked Petri net,

- IS: $\mathrm{P} \rightarrow \mathrm{Q}^{+} \times\left(\mathrm{Q}^{+} \cup\{+\infty\}\right)$

$$
\mathrm{p}_{\mathrm{i}} \rightarrow \mathrm{IS}_{\mathrm{i}}=\left[\mathrm{a}_{\mathrm{i}}, \mathrm{b}_{\mathrm{i}}\right] \text { with } 0 \leq \mathrm{a}_{\mathrm{i}} \leq \mathrm{b}_{\mathrm{i}} \text {. }
$$

$\mathrm{IS}_{\mathrm{i}}$ defines the static interval of staying time of a mark in the place $p_{i}$ belonging to the set of places $\mathrm{P}\left(\mathrm{Q}^{+}\right.$is the set of positive rational numbers). A mark in the place $p_{i}$ is taken into account in transition validation when it has stayed in $p_{i}$ at least a duration $a_{i}$ and no longer than $b_{i}$. After the duration $b_{i}$ the token will be dead.

The semantic specificity of P-time Petri nets was studied by Boyer and Roux [3].

Let us denote by:

- $\mathrm{t}_{\mathrm{i}}{ }^{\mathrm{o}}$ (resp. ${ }^{\circ} \mathrm{t}_{\mathrm{i}}$ ): the output places of the transition $t_{i}$ (resp. the input places of the transition $t_{i}$ ),

- $\mathrm{p}_{\mathrm{i}}{ }^{\circ}\left(\right.$ resp. $\left.{ }^{\circ} \mathrm{p}_{\mathrm{i}}\right)$ : the output transitions of the place $p_{j}$ (resp. the input transitions of the place $\mathrm{p}_{\mathrm{i}}$ ), $\mathrm{q}_{\mathrm{i}}$ : the expected sojourn time of the token in the place $\mathrm{p}_{\mathrm{i}}$,

- $\mathrm{q}_{\mathrm{i}}$ : the effective sojourn time of the token in the place $\mathrm{p}_{\mathrm{i}}$,

- $\quad \mathrm{St}_{\mathrm{ie}}(\mathrm{n})$ : the expected $\mathrm{n}^{\text {nd }}$ firing instant of the transition $t_{i}$.

- $\quad \mathrm{St}_{\mathrm{i}}(\mathrm{n})$ : the effective $\mathrm{n}^{\text {nd }}$ firing instant of the transition $t_{i}$.

\subsection{Formalization of the synchronization problem}

Let us express the condition of "as soon as possible functioning" of the P-time-Petri net corresponding to the Figure 1.

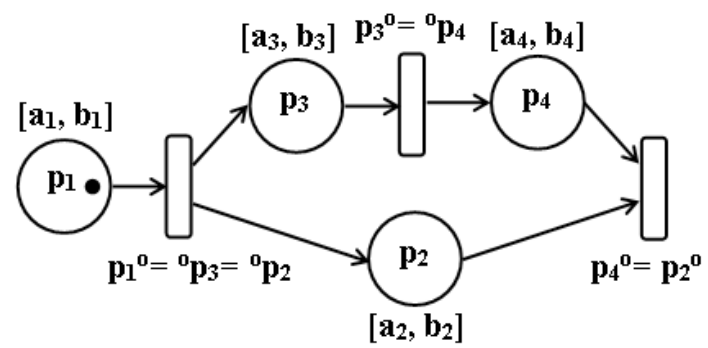

Figure 1. Synchronization problem

$$
\begin{aligned}
& \left\{\begin{array}{l}
S^{o} p_{3}=S^{o} p_{2} \\
S p_{2}^{o}=S p_{4}^{o} \\
S^{o} p_{4}=S^{o} p_{3}+a_{3} \\
S p_{2}^{o}=S^{o} p_{2}+q_{2} \\
S p_{4}^{o}=S^{o} p_{4}+q_{4}
\end{array}\right. \\
& \left\{\begin{array}{l}
a_{3}+b_{4} \geq a_{2} \\
a_{3}+a_{4} \leq b_{2}
\end{array}\right.
\end{aligned}
$$

The first two lines of the system (1) correspond respectively to parallelism and synchronization transitions constraints. The three following ones correspond to the description of the sequence of transitions firing imposed by the net structure. However, the third line has a particular form corresponding to the "as soon as possible" transition firing policy.

Actually, the general existence conditions for a functioning are (see [11]):

$\left\{\begin{array}{l}a_{3}+a_{4} \leq b_{2} \\ b_{3}+b_{4} \geq a_{2}\end{array}\right.$ 
Now, the conditions associated to a valid functioning which is different from the "as soon as possible functioning" are:

$$
\left\{\begin{array}{l}
a_{3}+a_{4} \leq b_{2} \\
a_{3}+b_{4}<a_{2} \\
b_{3}+b_{4} \geq a_{2}
\end{array}\right.
$$

It is easy to see that in the general cases, when the first equation of the system of equation (4) is true and the second one is false, the third one can be true!

As an example, let us consider the set of values: $\left(a_{2}, b_{2}, a_{3}, b_{3}, a_{4}, b_{4}\right)=(16,20,5,10,5,10)$.

In this case, the system of equation (1) has no solution whereas the system of equation (4) is verified. Actually, keeping the same values of other parameters, the same results can be provided by any value of $a_{2}$ such: $a_{2} \in[15,20]$. As a consequence, there is an infinite number of valid functioning, but no one of them is using the "as soon as possible" transition firing policy, when we use the above set of values and a free variable for $\mathrm{a}_{2}$.

As a summary, when a designer claims that the "as soon as possible" policy is valid for the transition firing of a maximum time constrained system, he would rather wait for a winter bus in the north of Canada: when the mathematical evidence is not enough, doing a real experimentation is the last solution.

More formally, when an optimal control loop is built on the "as soon as possible functioning" existence assumption, it must be clear that we are talking about the optimal solution of the restriction of the system where the "as soon as possible functioning" is valid. Actually, this control loop is not proved to be the solution of the system.

\section{Functional decomposition}

A workshop in repetitive functioning mode is modeled by a Strongly Connected Event Graph (SCEG) $[11,12]$.

\section{Definition 1}

An Event Graph (EG) is a particular Petri net in which each place has exactly one input transition and one output transition.

\section{Definition 2}

An EG is a SCEG if and only if it exists an oriented path connecting each node to another.
Performances of a SCEG running in monoperiodic functioning mode are proved to be the same as when using the K-periodic functioning $[11,12]$. Consequently, a mono-periodic functioning is used in order to decrease the complexity of the supervisory problem $[4,12]$. In this case, for each transition $\mathrm{t}, \mathrm{St}_{\mathrm{e}}(\mathrm{n}+1)=\mathrm{St}_{\mathrm{e}}(\mathrm{n})+\pi_{0}$ where $\pi_{0}$ is the period of the periodic functioning of the given discrete event system. In this paper, the scheduling task is supposed to be done. Therefore, the SCEG corresponding to the system is provided. Moreover, the setting of transitions firing instants is fixed too. Then, the robustness facing time disturbances will be studied in the following. The problem of time disturbances observability is not considered. It was studied in $[7,8,9]$.

As the sojourn times in places have not the same functional signification when they are included in the sequential process of a product or when they are associated to a free resource, a decomposition of the P-time Petri net model into four sets is made. The assumption of multi-product job-shops without assembling tasks is used:

- $\quad R_{U}$ is the set of places representing the used machines,

- $\mathrm{R}_{\mathrm{N}}$ corresponds to the set of places representing the free machines which are shared between manufacturing circuits,

- Trans $_{C}$ is the set of places representing the loaded transport resources,

- Trans $_{\mathrm{NC}}$ is the set of places representing the unloaded transport resources (or the interconnected buffers).

Figure 2 shows a P-time Petri net (G) modeling a system composed by two sequential processes $\mathrm{GO}_{1}$ and $\mathrm{GO}_{2}$ with two shared machines $\left(\mathrm{M}_{1}, \mathrm{M}_{2}\right)$, where: $\mathrm{R}_{\mathrm{U}}=\left\{\mathrm{p}_{2}, \mathrm{p}_{4}, \mathrm{p}_{11}, \mathrm{p}_{13}, \mathrm{p}_{15}\right\}, \mathrm{R}_{\mathrm{N}}=\left\{\mathrm{p}_{6}, \mathrm{p}_{7}, \mathrm{p}_{8}\right.$, $\left.\mathrm{p}_{9}\right\}$, Trans $\mathrm{C}_{\mathrm{C}}=\left\{\mathrm{p}_{1}, \mathrm{p}_{3}, \mathrm{p}_{10}, \mathrm{p}_{12}, \mathrm{p}_{14}\right\}$, Trans $\mathrm{NC}=\left\{\mathrm{p}_{5}\right.$, $\left.\mathrm{p}_{16}\right\}, \mathrm{GO}_{1}=\left(\mathrm{t}_{12}, \mathrm{p}_{10}, \mathrm{t}_{6}, \mathrm{p}_{11}, \mathrm{t}_{7}, \mathrm{p}_{12}, \mathrm{t}_{8}, \mathrm{p}_{13}, \mathrm{t}_{9}, \mathrm{p}_{14}, \mathrm{t}_{10}\right.$, $\left.\mathrm{p}_{15}, \mathrm{t}_{11}\right)$ and $\mathrm{GO}_{2}=\left(\mathrm{t}_{5}, \mathrm{p}_{1}, \mathrm{t}_{1}, \mathrm{p}_{2}, \mathrm{t}_{2}, \mathrm{p}_{3}, \mathrm{t}_{3}, \mathrm{p}_{4}, \mathrm{t}_{4}\right)$.

The intervals $\left(\mathrm{IS}_{\mathrm{i}}\right)$ and the expected staying times $\left(\mathrm{q}_{\mathrm{ie}}\right)$ associated to the places $\left(\mathrm{p}_{\mathrm{i}}\right)$ are: $\mathrm{IS}_{1}=[30,50]$, $\mathrm{q}_{1 \mathrm{e}}=38, \mathrm{IS}_{2}=[5,12], \mathrm{q}_{2 \mathrm{e}}=7, \mathrm{IS}_{3}=[10,20], \mathrm{q}_{3 \mathrm{e}}=15$, $\mathrm{IS}_{4}=[5,20], \mathrm{q}_{4 \mathrm{e}}=10, \mathrm{IS}_{5}=[1,+\infty], \mathrm{q}_{5 \mathrm{e}}=10, \mathrm{IS}_{6}=[0$, $+\infty], \mathrm{q}_{6 \mathrm{e}}=5, \mathrm{IS}_{7}=[0,+\infty], \mathrm{q}_{7 \mathrm{e}}=8, \mathrm{IS}_{8}=[8,+\infty]$, $\mathrm{q}_{8 \mathrm{e}}=13, \mathrm{IS}_{9}=[8,+\infty], \mathrm{q}_{9 \mathrm{e}}=15, \mathrm{IS}_{10}=[5,15], \mathrm{q}_{10 \mathrm{e}}=12$, $\mathrm{IS}_{11}=[15,20], \mathrm{q}_{11 \mathrm{e}}=17, \mathrm{IS}_{12}=[3,7], \mathrm{q}_{12 \mathrm{e}}=6, \mathrm{IS}_{13}=[2$, 20], $\mathrm{q}_{13 \mathrm{e}}=5, \mathrm{IS}_{14}=[2,7], \mathrm{q}_{14 \mathrm{e}}=5, \mathrm{IS}_{15}=[15,20]$, $\mathrm{q}_{15 \mathrm{e}}=16, \mathrm{IS}_{16}=[1,+\infty]$ and $\mathrm{q}_{16 \mathrm{e}}=19$. 

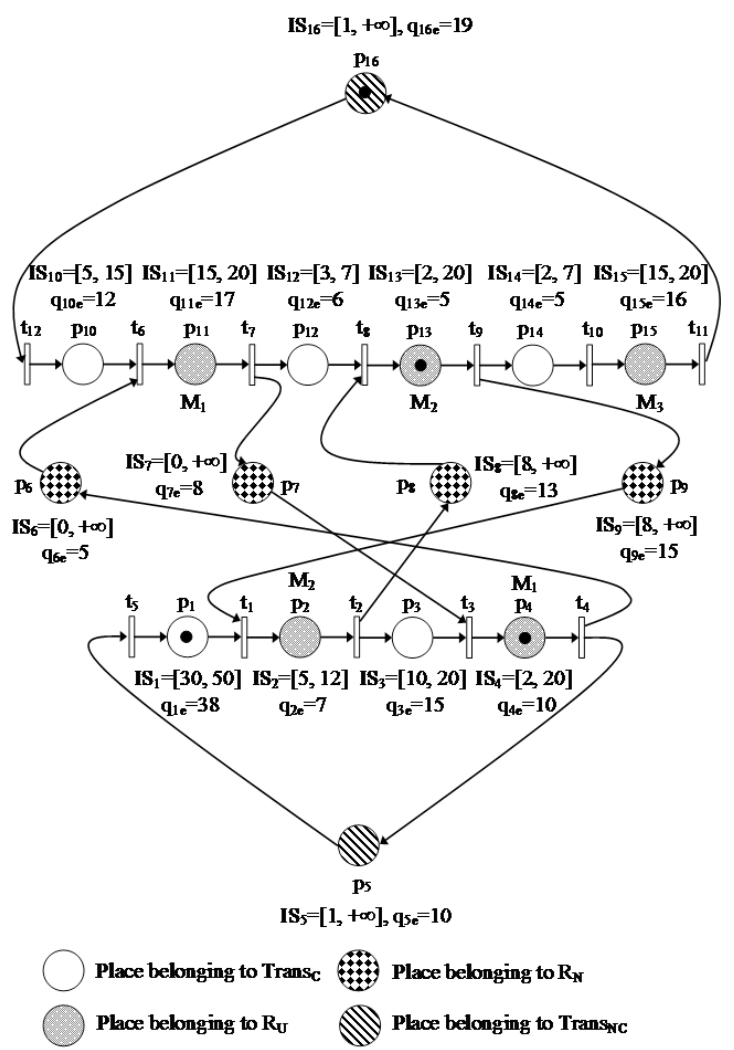

Figure 2. Functional decomposition

The initial expected firing instants of each transition are: $\mathrm{St}_{1 \mathrm{e}}(1)=15, \mathrm{St}_{2 \mathrm{e}}(1)=22, \mathrm{St}_{3 \mathrm{e}}(1)=37$, $\mathrm{St}_{4 \mathrm{e}}(1)=7, \mathrm{St}_{5 \mathrm{e}}(1)=17, \mathrm{St}_{6 \mathrm{e}}(1)=12, \mathrm{St}_{7 \mathrm{e}}(1)=29$, $\mathrm{St}_{8 \mathrm{e}}(1)=35, \mathrm{St}_{9 \mathrm{e}}(1)=0, \mathrm{St}_{10 \mathrm{e}}(1)=5, \mathrm{St}_{11 \mathrm{e}}(1)=21$ and $\mathrm{St}_{12 \mathrm{e}}(1)=0$.

The repetitive functioning mode is characterized by the period $\pi_{0}=40$.

\section{Definition 3 [10]}

A mono-synchronized subpath is a path containing one and only one synchronization transition which is its last node.

\section{Definition 4 [10]}

An elementary mono-synchronized subpath is a mono-synchronized subpath beginning with a place $p$ such as ${ }^{\circ} p$ is a synchronization transition.

In Figure 2, there are eight elementary monosynchronized subpaths constituting a partition of G: $\mathrm{Lp}_{1}=\left(\mathrm{p}_{13}, \mathrm{t}_{9}, \mathrm{p}_{14}, \mathrm{t}_{10}, \mathrm{p}_{15}, \mathrm{t}_{11}, \mathrm{p}_{16}, \mathrm{t}_{12}, \mathrm{p}_{10}, \mathrm{t}_{6}\right)$, $\mathrm{Lp}_{2}=\left(\mathrm{p}_{13}, \mathrm{t}_{9}, \mathrm{p}_{9}, \mathrm{t}_{1}\right), \mathrm{Lp}_{3}=\left(\mathrm{p}_{2}, \mathrm{t}_{2}, \mathrm{p}_{3}, \mathrm{t}_{3}\right), \mathrm{Lp}_{4}=\left(\mathrm{p}_{2}, \mathrm{t}_{2}\right.$, $\left.\mathrm{p}_{8}, \mathrm{t}_{8}\right), \mathrm{Lp}_{5}=\left(\mathrm{p}_{4}, \mathrm{t}_{4}, \mathrm{p}_{5}, \mathrm{t}_{5}, \mathrm{p}_{1}, \mathrm{t}_{1}\right), \mathrm{Lp}_{6}=\left(\mathrm{p}_{4}, \mathrm{t}_{4}, \mathrm{p}_{6}, \mathrm{t}_{6}\right)$, $\mathrm{Lp}_{7}=\left(\mathrm{p}_{11}, \mathrm{t}_{7}, \mathrm{p}_{7}, \mathrm{t}_{3}\right)$ and $\mathrm{Lp}_{8}=\left(\mathrm{p}_{11}, \mathrm{t}_{7}, \mathrm{p}_{12}, \mathrm{t}_{8}\right)$.

\section{Passive robustness computation}

The robustness of a system can be defined as its ability to preserve the specifications facing some expected or unexpected variations. So, the robustness of a system characterizes its capacity to deal with disturbances. Active robustness uses observed time disturbances to modify the control loop in order to satisfy these specifications $[6,15]$. On the other hand, passive robustness is based upon variations included in validity time intervals $[10,14]$. There is no control loop modification to preserve the required specifications. In this paper, we are interested in passive robustness computation for an advance time disturbance.

\subsection{Local passive robustness}

Let $\mathrm{Lp}_{\mathrm{k}}$ be a mono-synchronized subpath, we denote by:

- $\quad p_{z}$ : the last place of $\mathrm{Lp}_{\mathrm{k}}$,

- $\delta \mathrm{a}_{\text {Lpk }}$ : the advance time disturbance accepted at the input of $\mathrm{Lp}_{\mathrm{k}}$,

- $\Delta \mathrm{ac}_{\mathrm{Lpk}}$ : the advance compensable margin of $\mathrm{Lp}_{\mathrm{k}}$,

- $\Delta \mathrm{at}_{\mathrm{Lpk}}:$ the advance transmissible margin available at the ouput of $\mathrm{Lp}_{\mathrm{k}}$.

According to the topology of the considered manufacturing systems, the place $\mathrm{p}_{\mathrm{z}}$ of $\mathrm{Lp}_{\mathrm{k}}$ verifies: $\mathrm{p}_{\mathrm{z}} \in \mathrm{R}_{\mathrm{N}}$ or $\mathrm{p}_{\mathrm{z}} \notin \mathrm{R}_{\mathrm{N}}$.

If $\mathrm{p}_{\mathrm{z}} \in \mathrm{R}_{\mathrm{N}}$, we are in the presence of a place representing a waiting machine. An advance time disturbance equals to $\left(\mathrm{q}_{\mathrm{ie}}-\mathrm{b}_{\mathrm{i}}\right)=-\infty$ can theoretically be allowed. It does not change the firing instant of the synchronization transition $\mathrm{p}_{z}{ }^{\circ}$ of $\mathrm{Lp}_{\mathrm{k}}$. Therefore, it is completely compensated and we have:

$\Delta \mathrm{ac}_{\mathrm{Lpk}}=\left(\mathrm{q}_{\mathrm{ie}}-\mathrm{b}_{\mathrm{i}}\right)=-\infty$.

It is a similar case when $L p_{k}$ contains a place $p_{i}$ belonging to Trans $\mathrm{NC}_{\mathrm{NC}}$ representing an unloaded transport resource (or an interconnected buffer).

If $\mathrm{p}_{\mathrm{z}} \notin \mathrm{R}_{\mathrm{N}}$, the place $\mathrm{p}_{\mathrm{i}}$, verifying $\mathrm{p}_{\mathrm{i}}^{\circ}=\mathrm{p}_{\mathrm{z}}^{\circ}$ and $p_{i} \notin L p_{k}$, is a place of $R_{N}$ (see Figure 3 ). The token in this place is available when its sojourn time is $q_{i}=a_{i}$. The margin $\left(a_{i}-q_{i e}\right)$ contributes to the advance transmissible margin $\Delta \mathrm{at}_{\mathrm{Lpk}}$. 
On the other hand, to not have a token death in $\mathrm{p}_{\mathrm{z}}$, the mark arriving in advance in this place must sojourn a maximum time $\mathrm{q}_{\mathrm{z}}=\mathrm{b}_{\mathrm{z}}$. The margin $\left(\mathrm{q}_{\mathrm{ze}}\right.$ $-b_{z}$ ) available in $p_{z}$ contributes to the advance compensable margin. The advance is compensated by the delay $\left(b_{z}-q_{z e}\right)$.

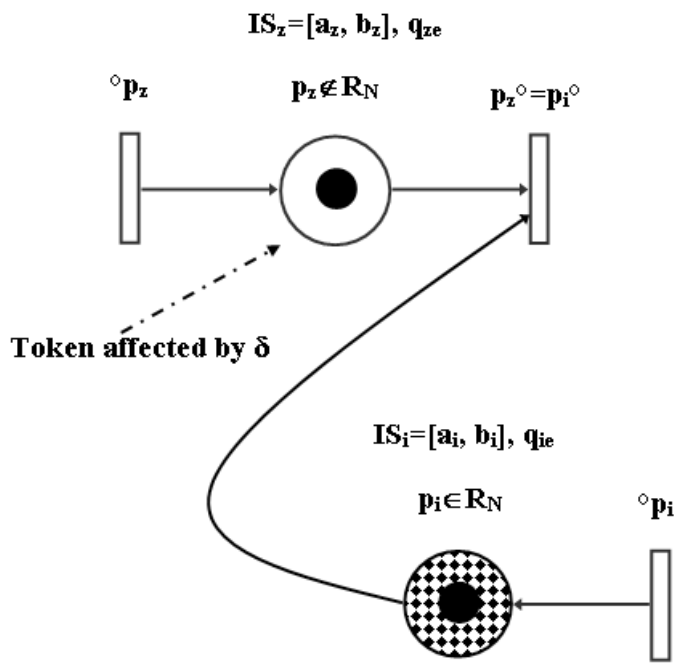

Figure 3. Local passive robustness for an advance time disturbance

Let us demonstrate that an advance time disturbance, $\delta=\left(\mathrm{q}_{\mathrm{ze}}-\mathrm{b}_{\mathrm{z}}\right)+\left(\mathrm{a}_{\mathrm{i}}-\mathrm{q}_{\mathrm{ie}}\right)$, does not cause a token death in $\mathrm{p}_{\mathrm{z}}$ and involves an advance on the firing instant of the transition $\mathrm{p}_{\mathrm{z}}^{\circ}$ equals to $\Delta \mathrm{at}_{\mathrm{Lpk}}=\left(\mathrm{a}_{\mathrm{i}}-\mathrm{q}_{\mathrm{ie}}\right)$. In other words, let us prove that when the effective sojourn time in $p_{z}$ is equal to $q_{z}$ $=b_{z}$, the effective sojourn time in $p_{i}$ is equal to $q_{i}$ $=\mathrm{a}_{\mathrm{i}}$. Therefore, the transition $\mathrm{p}_{\mathrm{z}}{ }^{\circ}$ can be fired and we have not a token death in $\mathrm{p}_{z}$.

We have:

$\left\{\begin{array}{l}S p_{z e}^{o}(n)=S^{o} p_{i e}(n)+q_{i e} \\ S p_{z e}^{o}(n)=S^{o} p_{z e}(n)+q_{z e}\end{array} \Rightarrow\right.$

$S^{o} p_{z e}(n)-S^{o} p_{i e}(n)=q_{i e}-q_{z e}$

$\left\{\begin{array}{l}S^{o} p_{z}(n)=S^{o} p_{z e}(n)+\delta \\ S p_{z}^{o}(n)=S^{o} p_{z}(n)+q_{z}=S^{o} p_{z}(n)+b_{z}\end{array} \Rightarrow\right.$

$S p_{z}^{o}(n)=S^{o} p_{z e}(n)+\delta+b_{z}$

$S p_{z}^{o}(n)=S^{o} p_{i e}(n)+q_{i} \Rightarrow$

$S^{o} p_{i e}(n)+q_{i}=S^{o} p_{z e}(n)+\delta+b_{z}$

Knowing the value of $\delta$, (5) and (7) give:

$$
\begin{aligned}
q_{i}= & q_{i e}-q_{z e}+\left(q_{z e}-b_{z}\right) \\
& +\left(a_{i}-q_{i e}\right)+b_{z} \quad \Rightarrow q_{i}=a_{i}
\end{aligned}
$$

The advance margin which is transmitted to $\left(\mathrm{p}_{\mathrm{z}}^{\circ}\right)^{\circ}$ is:

$$
\begin{aligned}
S p_{z}^{\circ}(n)-S p_{z \varepsilon}^{\circ}(n) & =\left(S^{\circ} p_{z \varepsilon}(n)+\delta+b_{z}\right) \\
& -\left(S^{\circ} p_{z \varepsilon}(n)+q_{z \varepsilon}\right)=a_{i}-q_{i \varepsilon}
\end{aligned}
$$

Finally, we conclude that:

$$
\begin{aligned}
\delta a_{L p k}= & \Delta a c_{L p k}+\Delta a t_{L p k} \\
\Delta a c_{L p k}= & \sum_{p_{i} \in L p_{k} \cap\left(R_{N} \cup \operatorname{Trans_{NC}}\right)}\left(q_{i \varepsilon}-b_{i}\right) \\
+ & {\left[\left(q_{z e}-b_{z}\right) \quad \text { if } p_{z} \notin R_{N}\right] } \\
\Delta a t_{L p k}= & \max \left(a_{i}-q_{i e}\right) \\
& p_{i}^{o}=p_{z}^{o} \\
& p_{i} \notin L p_{k} \\
& p_{i} \in R_{N}
\end{aligned}
$$

Table 1 gives the local passive robustness advance margins regarding the elementary monosynchronized subpaths of the P-time Petri net $G$ of Figure 2.

Table 1. Local passive robustness advance margins of elementary mono-synchronized subpaths

\begin{tabular}{|c|c|c|c|}
\hline $\begin{array}{c}\text { Elementary } \\
\text { mono- } \\
\text { synchronized } \\
\text { subpaths }\end{array}$ & $\Delta \mathbf{a c}_{\mathrm{Lpk}}$ & $\Delta \mathbf{a t}_{\mathrm{Lpk}}$ & $\delta \mathbf{a}_{\mathrm{Lpk}}$ \\
\hline $\mathrm{Lp}_{1}$ & $-\infty$ & -5 & $-\infty$ \\
\hline $\mathrm{Lp}_{2}$ & $-\infty$ & 0 & $-\infty$ \\
\hline $\mathrm{Lp}_{3}$ & -5 & -8 & -13 \\
\hline $\mathrm{Lp}_{4}$ & $-\infty$ & 0 & $-\infty$ \\
\hline $\mathrm{Lp}_{5}$ & $-\infty$ & -7 & $-\infty$ \\
\hline $\mathrm{Lp}_{6}$ & $-\infty$ & 0 & $-\infty$ \\
\hline $\mathrm{Lp}_{7}$ & $-\infty$ & 0 & $-\infty$ \\
\hline $\mathrm{Lp}_{8}$ & -1 & -5 & -6 \\
\hline
\end{tabular}

\subsection{Algorithm}

The proposed algorithm computes a passive robustness margin for an advance time disturbance, noted $\mathrm{APRM}_{\text {tn }}$, at a considered transition $t_{n}$. That is to say, the propagation from the transition $t_{n}$ of an advance time disturbance belonging to the interval $\left[\mathrm{APRM}_{\mathrm{tn}}, 0\right]$ does not involve any constraints violation.

Used notations:

- $\mathrm{C}_{\mathrm{ms}}$ is the set of mono-synchronized subpaths,

- $\mathrm{C}_{\mathrm{se}}$ is the set of elementary monosynchronized subpaths, 
- $\quad \mathrm{IN}\left(L \mathrm{p}_{\mathrm{j}}\right)$ is the first node of the path $L \mathrm{p}_{\mathrm{j}}$,

- $\operatorname{OUT}\left(L p_{j}\right)$ is the last node of the path $L p_{j}$.

The elaborated algorithm is the following:

$\varphi=\left\{\mathrm{Lp}_{\mathrm{j}} /\left(\mathrm{t}_{\mathrm{n}}={ }^{\circ} \mathrm{IN}\left(\mathrm{Lp}_{\mathrm{j}}\right)\right) \wedge\left(\mathrm{Lp}_{\mathrm{j}} \in \mathrm{C}_{\mathrm{ms}}\right) \wedge\left(\mathrm{Lp}_{\mathrm{j}} \in \mathrm{G}\right)\right\}$

$\mathrm{APRM}_{\mathrm{tn}} \Leftarrow \max _{\mathrm{j}}\left[\Delta \mathrm{ac}_{\mathrm{L}_{\mathrm{pj}}}\right.$

$\left.+F\left(G \backslash L p_{j}, O U T\left(L p_{j}\right)^{\circ}, \max \left(a_{i}-q_{i e}\right)\right)\right]$

$\mathrm{p}_{\mathrm{i}}^{\circ}=\mathrm{OUT}\left(\mathrm{Lp}_{\mathrm{j}}\right)$

$\mathrm{p}_{\mathrm{i}} \notin \mathrm{L} \mathrm{p}_{\mathrm{j}}$

$\mathrm{p}_{\mathrm{i}} \in \mathrm{R}_{\mathrm{N}}$

$\mathrm{F}\left(\mathrm{G}^{*}, \mathrm{p}^{*}, \Delta \mathrm{at}\right)$

\{

$\varphi^{*}=\left\{\mathrm{Lp}_{\mathrm{j}} /\left(\mathrm{p}^{*} \in \mathrm{Lp}_{\mathrm{j}}\right) \wedge\left(\mathrm{Lp}_{\mathrm{j}} \in \mathrm{C}_{\mathrm{se}}\right) \wedge\left(\mathrm{Lp}_{\mathrm{j}} \in \mathrm{G}^{*}\right)\right\}$

If $\left(\varphi^{*}=\Phi\right.$ or $\left.\Delta \mathrm{at}=0\right)$ then $(\mathrm{F} \Leftarrow \Delta \mathrm{at})$

Else

\{

$\mathrm{F} \Leftarrow \max _{\mathrm{j}}\left\{\max \left[\Delta \mathrm{at},\left(\Delta \mathrm{ac}_{\mathrm{Lpj}}\right.\right.\right.$

$\left.+F\left(G^{*} L_{p_{j}}, \operatorname{OUT}\left(L_{p_{j}}\right)^{\circ}, \max \left(a_{i}-q_{i e}\right)\right)\right]$

$\mathrm{p}_{\mathrm{i}}^{\circ}=\mathrm{OUT}\left(\mathrm{Lp}_{\mathrm{j}}\right)$

$\mathrm{p}_{\mathrm{i}} \notin \mathrm{L} \mathrm{p}_{\mathrm{j}}$

$\mathrm{p}_{\mathrm{i}} \in \mathrm{R}_{\mathrm{N}}$

\}

\}

\section{Description}

From the transition $t_{n}$, we build the set of monosynchronized subpaths $\varphi$ :

$\varphi=\left\{\mathrm{Lp}_{\mathrm{j}} /\left(\mathrm{t}_{\mathrm{n}}={ }^{\circ} \mathrm{IN}\left(\mathrm{Lp}_{\mathrm{j}}\right)\right) \wedge\left(\mathrm{L}^{*} \mathrm{p}_{\mathrm{j}} \in \mathrm{C}_{\mathrm{ms}}\right) \wedge\left(\mathrm{Lp}_{\mathrm{j}} \in \mathrm{G}\right)\right\}$.

In the considered topology, $\varphi$ is constituted by one or two mono-synchronized subpaths.

If $\varphi$ contains two mono-synchronized subpaths then we take the max of the computed margins.

The computation of the value of $\mathrm{APRM}_{\mathrm{tn}}$ is made by using a recursive function $\mathrm{F}\left(\mathrm{G}^{*}, \mathrm{p}^{*}, \Delta \mathrm{at}\right)$.

$\mathrm{F}\left(\mathrm{G}^{*}, \mathrm{p}^{*}, \Delta \mathrm{at}\right)$ has three parameters. For the first time, it is calculated for each $\mathrm{Lp}_{\mathrm{j}} \in \varphi$ with:

$\mathrm{G}^{*}=\mathrm{G} \backslash \mathrm{Lp}_{\mathrm{j}}$

$\mathrm{p}^{*}=\operatorname{OUT}\left(\mathrm{Lp}_{\mathrm{j}}\right)^{\mathrm{o}}$

$$
\begin{aligned}
\Delta a t=\Delta a t_{L_{p j}}= & \max \left(a_{i}-q_{i e}\right) \\
& p_{i}^{\circ}=\operatorname{OUT}\left(L_{p_{j}}\right) \\
& p_{i} \notin \mathrm{Lp}_{j} \\
& \mathrm{p}_{\mathrm{i}} \in \mathrm{R}_{\mathrm{N}}
\end{aligned}
$$

$\varphi^{*}$ is a set of elementary mono-synchronized subpaths belonging to $\mathrm{G}^{*}$ and starting with $\mathrm{p}^{*}$. The stop condition of the algorithm is:

$\left(\varphi^{*}==\Phi\right.$ or $\left.\Delta \mathrm{at}==0\right)$.

\section{Example 1}

Let us apply the algorithm at the transition $\mathrm{t}_{12}$ of Figure 2.

$\varphi=\left\{\mathrm{Lp}^{\prime}=\left(\mathrm{p}_{10}, \mathrm{t}_{6}\right)\right\}$

$\Delta \mathrm{ac}_{\mathrm{Lp}},=\mathrm{q}_{10 \mathrm{e}}-\mathrm{b}_{10}=-3$

$\Delta \mathrm{at}_{\mathrm{Lp}},=\mathrm{a}_{6}-\mathrm{q}_{6 \mathrm{e}}=-5$

APRM $_{\mathrm{t} 12} \Leftarrow\left(-3+\mathrm{F}\left(\mathrm{G} \backslash \mathrm{Lp} \mathrm{p}^{\prime}, \mathrm{p}_{11},-5\right)\right)$

$\varphi^{*}=\left\{\mathrm{Lp}_{7}, \mathrm{Lp}_{8}\right\}$

$L p_{7}=\left(p_{11}, t_{7}, p_{7}, t_{3}\right), L p_{8}=\left(p_{11}, t_{7}, p_{12}, t_{8}\right)$

$\mathrm{F}\left(\mathrm{G} \backslash \mathrm{Lp} \mathrm{p}^{\prime}, \mathrm{p}_{11},-5\right) \Leftarrow$

$\max \left\{\begin{array}{l}\max \left[-5,-\infty+F\left(G \backslash L p^{\prime} \backslash L p_{7}, p_{4}, 0\right)\right] \\ \max \left[-5,-1+F\left(G \backslash L p^{\prime} \backslash L p_{8}, p_{13},-5\right)\right]\end{array}\right.$

Step 1:

$$
\begin{aligned}
& \mathrm{F}\left(\mathrm{G} \backslash L \mathrm{p}^{\prime} \backslash \mathrm{L} \mathrm{p}_{4}, \mathrm{p}_{4}, 0\right) \Leftarrow 0 \\
& \max \left[-5,-\infty+\mathrm{F}\left(\mathrm{G} \backslash L \mathrm{Lp}^{\prime} \backslash \mathrm{Lp}_{4}, \mathrm{p}_{4}, 0\right)\right]=-5
\end{aligned}
$$

Step 2:

$$
\begin{gathered}
\varphi^{*}=\left\{\mathrm{Lp}_{2}\right\} \\
\mathrm{L} \mathrm{p}_{2}=\left(\mathrm{p}_{13}, \mathrm{t}_{9}, \mathrm{p}_{9}, \mathrm{t}_{1}\right) \\
\mathrm{F}\left(\mathrm{G} \backslash \mathrm{L} \mathrm{p}^{\prime} \backslash \mathrm{Lp}_{8}, \mathrm{p}_{13^{\prime}},-5\right) \Leftarrow \\
\max \left[-5,-\infty+\mathrm{F}\left(\mathrm{G} \backslash \mathrm{L} \mathrm{p}^{\prime} \backslash \mathrm{Lp}_{8} \backslash \mathrm{Lp}_{2}, \mathrm{p}_{2}, 0\right)\right] \\
\mathrm{F}\left(\mathrm{G} \backslash \mathrm{L} \mathrm{p}^{\prime} \backslash \mathrm{Lp}_{8} \backslash \mathrm{Lp}_{2}, \mathrm{p}_{2}, 0\right) \Leftarrow 0 \\
\mathrm{~F}\left(\mathrm{G} \backslash \mathrm{L} \mathrm{p}^{\prime} \backslash \mathrm{L} \mathrm{p}_{8}, \mathrm{p}_{13},-5\right) \Leftarrow-5 \\
\max \left[-5,-1+\mathrm{F}\left(\mathrm{G} \backslash \mathrm{L} \mathrm{p}^{\prime} \backslash \mathrm{L} \mathrm{p}_{8}, \mathrm{p}_{13},-5\right)\right]=-5 \\
\mathrm{~F}\left(\mathrm{G} \backslash \mathrm{L} \mathrm{p}^{\prime}, \mathrm{p}_{11},-5\right) \Leftarrow \max (-5,-5)=-5
\end{gathered}
$$

$\mathrm{APRM}_{\mathrm{t} 12} \Leftarrow-8$

\subsection{Constraints violation lemma}

The preceding algorithm does not take into account the constraints of the disturbance occurrence node. A lemma is provided for this purpose when the disturbance occurrence is at the transition where $\mathrm{APRM}_{\mathrm{tn}}$ is calculated. Therefore, we take the max of the available margins in the case of an advance time disturbance. 
We define a function $\mathrm{g}_{\mathrm{a}}$ as follows:

$$
\begin{aligned}
& \mathrm{g}_{\mathrm{a}}: \mathrm{P} \rightarrow \mathrm{Q}^{-} \\
& p_{i} \mapsto g_{a}\left(p_{i}\right)= \begin{cases}0 & \text { if } q_{i}<a_{i} \\
q_{i}-q_{i e} & \text { if } a_{i} \leq q_{i}<q_{i e} . \\
0 & \text { if } q_{i e} \leq q_{i} \leq b_{i}\end{cases}
\end{aligned}
$$

\section{Lemma}

The occurrence of a disturbance $\delta$ at a transition $\mathrm{t}_{\mathrm{n}}$ does not involve any constraints violation in ${ }^{\circ} \mathrm{t}_{\mathrm{n}}$ if $\delta \in\left[\Delta_{\text {min }}, \Delta_{\text {max }}\right]$, where:

$$
\begin{gathered}
\Delta_{\min }=\max ^{\circ} g_{a}\left(p_{i}\right) \\
p_{i}^{\circ}=t_{n} \\
\Delta_{\max }=\min \left(b_{i}-q_{i e}\right) \\
p_{i}^{\circ}=t_{n}
\end{gathered}
$$

\section{Proof:}

- Case of an advance time disturbance:

The function $g_{a}$ makes a test on the effective sojourn time $\mathrm{q}_{\mathrm{i}}$.

If $q_{i}<a_{i}$, the token in $p_{i}$ is not available and any advance on the firing instant of $t_{n}$ involves a constraint violation. Hence, $g_{a}\left(p_{i}\right)=0$.

If $a_{i} \leq q_{i}<q_{i e}$, we have an advance margin equals to $\mathrm{g}_{\mathrm{a}}\left(\mathrm{p}_{\mathrm{i}}\right)=\mathrm{q}_{\mathrm{i}}-\mathrm{q}_{\mathrm{ie}}$. The transition $\mathrm{t}_{\mathrm{n}}$ can be fired without any constraints violation.

If $\mathrm{q}_{\mathrm{i}}=\mathrm{q}_{\mathrm{ie}}$, there is no advance margin available since the token in $\mathrm{p}_{\mathrm{i}}$ has sojourned its allocated time. So, $\Delta_{\min }=\mathrm{g}_{\mathrm{a}}\left(\mathrm{p}_{\mathrm{i}}\right)=0$.

If $t_{n}$ is a synchronization transition, we must apply the max as in (13).

- Case of a delay time disturbance:

If $\mathrm{q}_{\mathrm{i}} \leq \mathrm{q}_{\mathrm{ie}}$, we can accept a delay on the firing instant of $t$ equals to $\left(b_{i}-q_{i e}\right)$.

If $t_{n}$ is a synchronization transition, we must apply the min as in (14).

\section{Example 2}

Let us consider the transition $t_{12}$ of Figure 4.

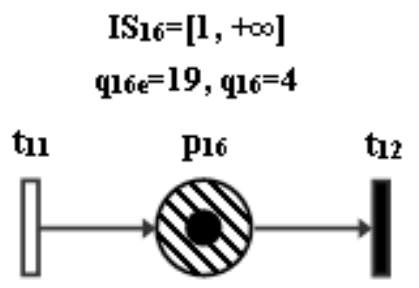

Figure 4. Constraints violation in ${ }^{\circ} \mathrm{t}_{12}$
The place $\mathrm{p}_{16}$ has a token with $\mathrm{q}_{16}=4$.

$\mathrm{g}_{\mathrm{a}}\left(\mathrm{p}_{16}\right)=4-19=-15$ and $\left(\mathrm{b}_{4}-\mathrm{q}_{4 \mathrm{e}}\right)=+\infty$. So, $\left[\Delta_{\min }, \Delta_{\max }\right]=[-15,+\infty]$.

The occurrence of a disturbance $\delta \in[-15,+\infty]$ does not cause any constraints violation in $\mathrm{p}_{16}$. Now, knowing that $\mathrm{APRM}_{\mathrm{t} 12}=-8$, any time disturbance $\delta \in[-8,0]$ does not cause any constraints violation, since $\max (-15,-8)=-8$.

\section{Example 3}

Let us consider the synchronization transition $\mathrm{t}_{1}$ of Figure 5.

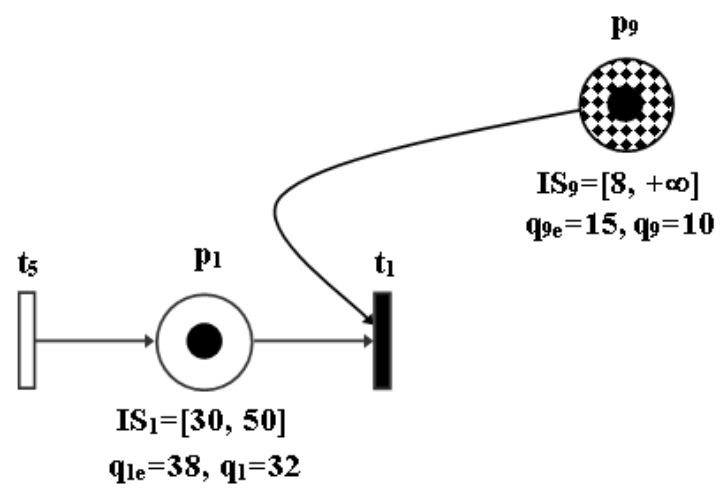

Figure 5. Constraints violation in ${ }^{\circ} t_{1}$

$\mathrm{p}_{1}^{\circ}=\mathrm{t}_{1} \Rightarrow \mathrm{g}_{\mathrm{a}}\left(\mathrm{p}_{1}\right)=32-38=-6$

$\left(\mathrm{b}_{1}-\mathrm{q}_{1 \mathrm{e}}\right)=50-38=12$

$\mathrm{p}_{9}^{\circ}=\mathrm{t}_{9} \Rightarrow \mathrm{g}_{\mathrm{a}}\left(\mathrm{p}_{9}\right)=10-15=-5$

$\left(\mathrm{b}_{9}-\mathrm{q}_{9 \mathrm{e}}\right)=+\infty$

$\Delta_{\text {min }}=\operatorname{maxg}_{\mathrm{a}}\left(\mathrm{p}_{\mathrm{i}}\right)=\max (-6,-5)=-5$

$\mathrm{p}_{\mathrm{i}}^{0}=\mathrm{t}_{1}$

$\Delta_{\text {max }}=\min \left(\mathrm{b}_{\mathrm{i}}-\mathrm{q}_{\mathrm{ie}}\right)=\min (12,+\infty)=12$

$\mathrm{p}_{\mathrm{i}}^{0}=\mathrm{t}_{1}$

$\left[\Delta_{\text {min }}, \Delta_{\max }\right]=[-5,12]$.

\section{Conclusion}

This paper is devoted to passive robustness in manufacturing job-shops with time constraints and notably to the passive robustness facing advance time disturbances. In such systems, the operation times are included between a minimum and a maximum value. P-time Petri nets are used for modeling.

An algorithm, allowing the computation of an advance passive robustness margin at a given transition, is elaborated relying on a study of the available local robustness at the synchronisation 
transition of a mono-synchronized subpath. Moreover, a lemma is provided in order to take into account the possibility of constraints violation at the input places of the transition where the margin is calculated. Therefore, the occurrence of an advance time disturbance respecting both the lemma conditions and the algorithm calculated margin does not involve any constraints violation and there is no control loop modification to preserve the required specifications. The established results are illustrated step by step on examples of a given workshop.

In future works, some proactive strategies will be studied in order to propose a global scheduling, integrating the detection of time disturbances which cannot be handled by the current structure of the event graph, and the proposition of another cyclic functioning structure compatible with the disturbance. The proof of a valid transient existence will be considered too.

\section{REFERENCES}

1. Amari, S., Demongodin, I., Loiseau, J.J. \& Martinez, C. (2012). Max-Plus Control Design for Temporal Constraints Meeting in Timed Event Graphs, IEEE Transactions on Automatic Control, Institute of Electrical and Electronics Engineers, 57(2), 462-467.

2. Becha, T., Hamri, H., Kara, R. \& CollartDutilleul, S. (2017). Model predictive control of an electroplating line without stopping the production, International Journal of Advanced Manufacturing Technology, 91(9-12), 4095-4105.

3. Boyer, M. \& Roux, O. H. (2008). On the compared expressiveness of Arc, Place and Transition Time Petri Nets, Fundamenta Informaticae, Polskie Towarzystwo Matematyczne, 88(3), 225-249.

4. Collart-Dutilleul, S., Denat, J.-P. \& Khansa, W. (1995). Use of Periodic Controlled Petri Net for Discrete Event Dynamical System Control Synthesis. In Proceedings of the ECC'95, Rome (pp. 2060-2065).

5. Declerck, P. (2016). Compromise approach for predictive control of Timed Event Graphs with specifications defined by P-time Event Graphs, Discrete Event Dynamic Systems, 26(4), 611-632.

6. Jerbi, N., Collart-Dutilleul, S., Craye, E. \& Benrejeb, M. (2009). Commande robuste des ateliers manufacturiers à contraintes de temps, Journal Européen des Systèmes Automatisés (JESA), 43(1-2), 7-33.

7. Jerbi, N., Collart-Dutilleul, S., Craye, E. \& Benrejeb, M. (2005). Observability of
Tolerant Multi-product Job-shops in Repetitive Functioning Mode. In $17^{\text {th }}$ IMACS Word Congress on Scientific Computation, Applied Mathematics and Simulation (IMACS'05), Paris.

8. Jerbi, N., Collart-Dutilleul, S., Craye, E. \& Benrejeb, M. (2007). Localization Algorithm of Time Disturbances in Tolerant Multi-product Jobshops, Studies in Informatics and Control, 16(1), 19-33.

9. Jerbi, N., Collart-Dutilleul, S., Craye, E. \& Benrejeb, M. (2006). Localization of Time Disturbances in Tolerant Multi-product Jobshops Without Assembling Tasks. In IMACS Multiconference on Computational Engineering in Systems Applications (CESA'06), Beijing (pp. 45-50).

10. Jerbi, N., Collart-Dutilleul, S., Craye, E. \& Benrejeb, M. (2004). Robust Control of Multiproduct Job-shops in Repetitive Functioning Mode. In IEEE Conference on Systems, Man, and Cybernetics (SMC'04), The Hague, Netherlands (pp. 4917-4922).

11. Khansa, W., Aygalinc, P. \& Denat, J.-P. (1996). Structural analysis of p-time Petri nets. In IMACS Multiconference on Computational Engineering in Systems Applications (CESA'96), Lille (pp. 127-136).

12. Laftit, S., Proth, J.-M. \& Xie, X. (1992). Optimisation of invariant criteria for event graphs, IEEE Transactions on Automatic Control, $37(5), 547-555$.

13. Lajmi, F., Talmoudi, A. J. \& Dhouibi, H. (2017). Fault Diagnosis of Uncertain Systems Based on Interval Fuzzy PETRI Net, Studies in Informatics and Control, 26(2), 239-248.

14. Mhalla, A., Collart-Dutilleul, S., Jerbi, N., Craye, E. \& Benrejeb, M. (2010). Passive Robustness in Milk Manufacturing Unit with Time Constraints, IFAC Proceedings Volumes, 43(17), 40-46.

15. Mhalla, A., Jerbi, N., Collart-Dutilleul, S., Craye, E. \& Benrejeb, M. (2013). Robust Control Strategies Facing Disturbances in Manufacturing Workshops with Time Constraints, Computers \& Industrial Engineering, 65(2), 268-276.

16. Zaghdoud, R., Mesghouni, K., Collart-Dutilleul, S., Zidi, K. \& Ghedira, K. (2015). A Hybrid Method for Assigning Containers to AGVs in the Dynamic Environment of Container Terminals, Studies in Informatics and Control, 24(1), 43-50.

17. Zhang, H., Collart-Dutilleul, S. \& Mesghouni, K. (2014). Cyclic Scheduling Steady-State Analysis and Improved Mathematical Models. In $19^{\text {th }}$ World Congress of the International Federation of Automatic Control, Cape Town, South Africa (pp. 24-29). 